\title{
Does Whole Body Vibration have Clinically Significant Neurophysiological and Neurovascular Implications?
}

\author{
Dan Robbins ${ }^{1, *}$, Edzard Zeins tra ${ }^{2}$, Alfonso Jimenez ${ }^{1}$, Mark Goss-Sampson ${ }^{1}$ \\ ${ }^{1}$ Centre for Sports Science and Human Performance, University of Greenwich, Chatham Maritime, Kent UK \\ ${ }^{2}$ Centre for Human Movement Sciences, University Medical Centre Groningen, University of Groningen, the Netherlands
}

\begin{abstract}
Whole body vibration has received much attention as an innovative approach to exerc ise, lead ing to constantly increasing attention from the scientific community. Previous research considering occupational vibration has illustrated the risks associated with high levels of exposure to vibration; however during vibration exercise the exposure duration is much shorter and therefore the potential complications must be reconsidered. This review brings together research from various aspects of occupational vibration, clinical research and vibration exercise to address issues within the context of health and safety with a particular focus on neurophysiological and neurovascular responses. The results indicate that peripheral nerve and blood vessels are exposed to risks such as compression, shear stress and altered function as a response to vibration. However, correct planning and implementation of exercise protocols should effectively control these risks. By summarising the areas that have received attention an overview of potential complications will be achieved; with an understanding of which factors prevent participation and those that simply require an amended approach to vibration exe rcise.
\end{abstract}

Keywords Whole-Body Vibration, Exercise, Nerve, Neurophysiology, Neurovascular

\section{Introduction}

The past decade has seen the publication of a series of reviews regarding whole body vibration (WBV), areas of focus have included: effectiveness in physical therapy[1-5] effectiveness in sport[5], muscle and bone health[6-8], effectiveness and potential benefits [8-10] and correct use of terminology[11]. However, while many of these reviews have addressed different applications of $\mathrm{WBV}$ research such as: muscle function, bone health, Parkinson's disease and effectiveness of WBV exercise per se. To the best of the author's knowledge, there has been no review paper specifically concerned with health and safety issues of WBV exercise to date. Previously, as far back as the 1950's, the relationship between low back pain and vibration has been reported $[1,12]$ subsequent to this there were a series of large population studies of workers exposed to occupational vibration during the 1980's[13]. For an effective analysis of the risks of vibration it is important to first establish a distinction between passive, or occupational, high exposure vibration and active, or training/exercise vibration. The former is a consequence of a work environment involving daily exposure over repeated hours and days, the latter is short duration exposure (minutes per week) as a consequence of a training or therapy regime.

* Corresponding author:

d.w.e.robbins@gmail.com (Dan Robbins)

Published online at http://journal.sapub.org/ijpt

Copyright (C) 2012 Scientific \& Academic Publishing. All Rights Reserved
An understanding of this training or therapeutic application is vital for safe and effective prescription of vibration exercise. The aim of this review is to amalgamate current literature on WBV relating to the advantages and potential complications not yet identified in previous publications. In order to address these is sues the application and effects of WBV for clinical conditions and general health promotion will be reviewed. The concept of identifying complications for WBV in this review is based around two approaches. Firstly to consider issues that have arisen from vibration that have previously been reported and secondly to address the issue of the exaggeration of pre-existing conditions. The combination of these two approaches will allow consideration of the implications and contraindications of vibration used as an exercise modality. Current WBV exercise equipment operates at a wide range of frequencies, typically vibration equipment used for the purpose of health and exercise will operate between a range 6-100 Hz and 0.3-16 g, which potentially can overlap with the vibrations frequencies met during industrial exposure. Therefore while the focus of this review is the relative risks associated with WBV exercise; examples from occupational vibration and pre-existing clinical conditions will be included.

\section{Research Methods}

A search was conducted using the following electronic databases: Google Scholar, PubMed and EBSCOhost. After an initial database search, additional searching via follow up 
of reference lists and key authors was undertaken. Key search words included: vibration and whole body vibration; which were used in combination with nerve, muscle, neuromuscular, neurophysiology, neuropathy, neurovascular, vascular, syndrome, palsy and injury. Articles were checked for relevant content and were included based on the following criteria: 1. published in English; 2. conference abstracts were excluded. 3. Article content should be related to vibration or conditions caused by - or aggravated by vibration.

\section{Neurophysiological Considerations}

The risks and consequences of occupational vibration have been acknowledged and addressed by researchers and government organisations, such as the UK's Health and Safety Executive, who provide information about the risks of industrial vibration and expos ure during work co mmit ments. This has been deemed necessary as both WBV and hand and arm vibration can lead to Hand and Arm Vibration Syndrome (HA VS) (http://www.hse.gov.uk/vibration/) and/or debilitating conditions such as back pain. In addition, there are various methods by which nerve inju ries can occur e.g. compression, traction, friction, often resulting from repetitive forceful motions in awkward or unusual positions [14] which are an integral part of sports activities, particularly during learning stages and/or regular participation that can be aggravated by vibration. Despite this the neurophysiological and neuromechanical implications with regards to vibration during exercise have still received scant attention. One area which has been investigated is the risks involved with excessive vibration during cycling. Regular cyclists, particularly those who receive higher levels of vibration e.g. off road cyclists, are at risk of upper limb compression neuropathy [15-18]. Nerve injury is more frequently seen in the ulnar nerve than the median nerve, $[19,20]$ with symptoms including weakness of grip and occasionally numbness of the fourth and fifth fingers[21]. Prevention or management of the condition, if caught early, is relatively simple with recommendations including: use of correct protective equipment (padded gloves and handlebars), ensuring the correct set up of the bicycle e.g. seat and handlebar positions, regularly changing the position of hands whilst riding[22]. Wilmarth \& Nelson[19] performed a prospective study before and immed iately after a four day $600 \mathrm{Km}$ bicycle race and found $70 \%$ of the study participants experienced either upper limb Ulnar nerve motor, sensory or both symptoms following the race. These considerations are particularly relevant with the current development of Power Plate Ltd's new PowerBIKE which has a vibrating mechanism. Of all the aetiological factors considered, the most common for ulnar nerve compression injuries is pressure on the heel of the hand during vibration[20]. This obviously applies to other exercise situations, such as during push ups where even performing the exercise on a hard floor has been shown to cause ulnar nerve injury,[23]. The presence of vibration, for example when completing push ups with hands on a vibrating platform, therefore increases the relative risk. This risk can again be exaggerated if the hands also receive impact e.g. during plyometric press ups, potentially leading to a debilitating condition of the ulnar nerve known as hypothenar hammer syndrome[21]. The Ulnar nerve is not the only nerve at risk during vibration exercise. During push ups participants are required to place their hands directly upon the platform in a position similar to that of the 'provocative positions' which are positions which exacerbate symptoms used in the clinical diagnosis. Examples of provocative positions in carpal tunnel syndrome are the "reverse Phalen's manoeuvre" (see Figure 1)

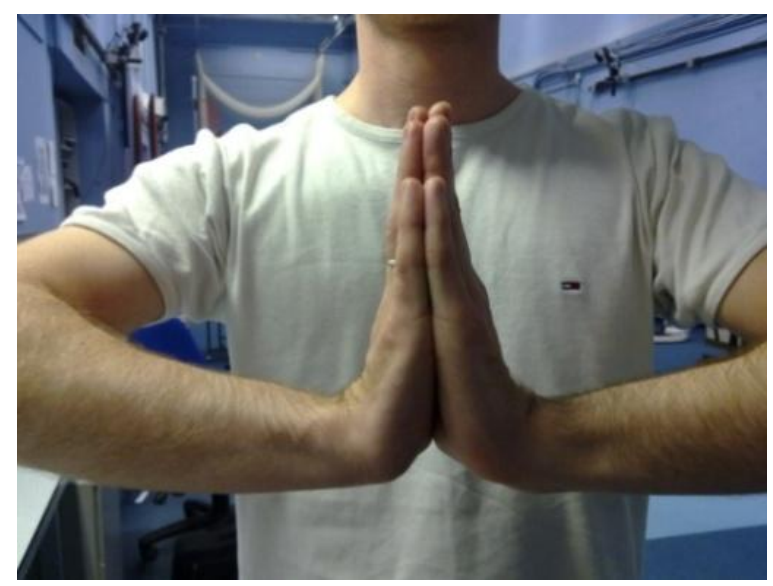

Figure 1. Reverse Phalen's manoeuvre

where hands are held at shoulder height, wrist extended, palms touching with fingers pointing to the ceiling and has been shown to produce significantly higher carpal tunnel pressures than the normal Phalen's manoeuvre which is flexed wrists with the backs of the hands placed together[24]; as this position is utilised for its ability to generate unusual or uncomfortable sensations. When combined with vibration it has potential to be an issue for carpal tunnel patients. Another test is the carpal compression test or Durkan's test where direct pressure is placed upon base of the palm just distal to the wrist [25] (see Figure 2).

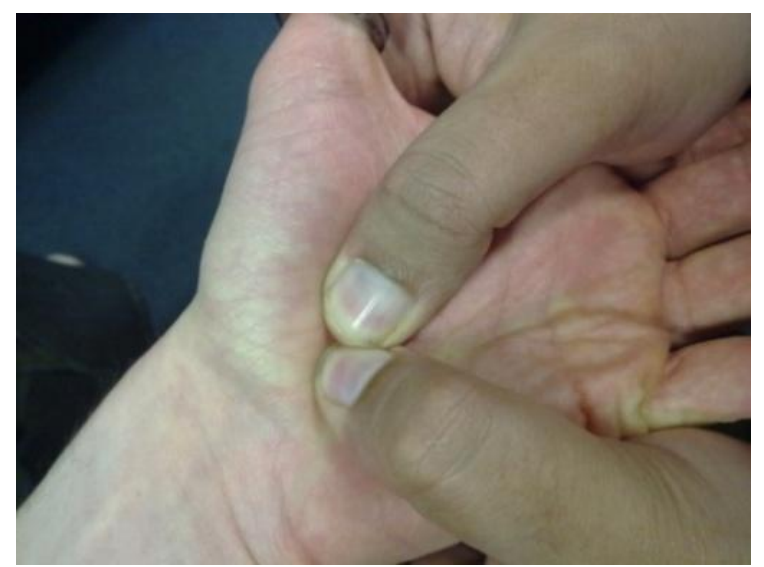

Figure 2. Durkan's Test

The carpal compression test has been shown to achieve a 
sensitivity of $87 \%$, and a specificity of $95 \%$ [26], again confirming the risks of added pressure if the participant has a pre-existing condition. Median nerve compression injuries at the wrist are reported in athletes who perform repetitive gripping or sustained wrist hyperflexion or hyperextension or who are exposed to vibration[14].

It should also be noted that the most severe nerve injury and structural changes (demyelination, interstitial and perineurial fibrosis) occur just proximal to the wrists [27]. If large diameter nerve fib res are affected prior to small fibres, and as is often the case in carpal tunnel syndrome[28]; then proprioceptive input will be reduced. In study considering the outcome of 55 carpal tunnel re lease operations performed due to vibration induced carpal tunnel syndrome, [29] found that the level of exposure prior to operation influenced the recovery after the surgery. These findings again confirm that neural structural changes occur in response to vibration. When considering the neurophysiological basis for nociceptive signals the gate theory suggested by[30] and further refined by [31], suggests that there is a control system at the spinal level help ing to modulate the signals transmitted to the brain. Essentially signals from small and large diameter fibres (noxious and non-noxious sensory signals respectively) initially communicate with an inhibitory interneuron within the spinal cord (see Figure 3).

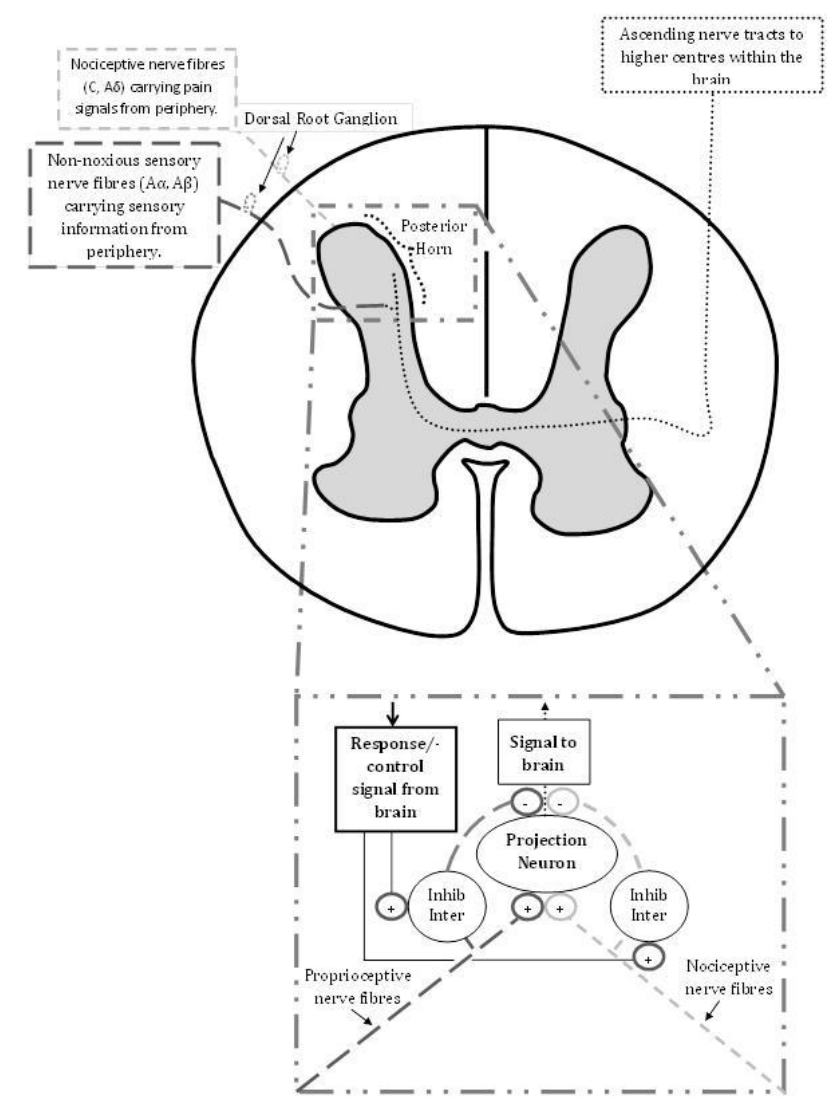

Figure 3. Representation of gate control theory of pain

These inhibitory interneurons alter the ratio of the final ascending signal sent from the projection neuron. This process therefore regulates the intensity of the signal travelling up the spine to the brain. Consequently, if large nerve fibres are less active, there is less inhibition of nociception. In this instance it is said 'the gate is open' (see Table 1 for examples of situations where the gate is open or closed). Given that some pathological conditions (such as peripheral neuropathies and carpal tunnel syndrome [28] have been shown to damage large nerve fibres prior to small nerve fibres, this potentially explains one underlying mechanism for some clinical populations finding vibration exercise unpleasant. Although the concept that finding vibration unpleas ant should not be restricted to clinical population, [32] reported most subjects felt uncomfortable after approximately five minutes of WBV if they were not allowed to change position. It should also be noted that when considering the effect of vibration on peripheral nerves, [33] suggested that the primary nerves affected by vibration white finger were the small nerve fibres. As nerve conduction studies displayed lower range sensory action potentials and nerve biopsies illustrated that neuronal damage had to be quite severe before large dia meter nerve fibres were affected, despite conclusions being based on a small sample group $(n=$ 6 ), the findings must be considered. A lack of nociceptive input decreases the effectiveness of the body's protective mechanis ms. This was recently confirmed in a study by [34] who tested a cohort of office and manual workers for effects of combined hand/arm vibration on nerve conduction, especially the conduction of the large diameter nerve fibres; no relationship between exposure and distal neuropathy was observed. While this would suggest that vibration induced injury is unlikely to result in a condition that will further 'open the gate', it has clearly been shown that carpal tunnel syndrome can result in increased pain levels. However, it must also be considered that any condition which previously resulted in damage to large nerve fibres has potential to 'open the gate'.

Table 1. Factors that regulate spinal gate control

\begin{tabular}{|c|c|c|}
\hline & Gate open & Gate Closed \\
\hline Physiological & $\begin{array}{c}\mathrm{A} \delta \text { and/or } \mathrm{C} \text { fibres } \\
\text { active } \\
\text { Overuse } \\
\text { Fatigue } \\
\text { Improper mechanics } \\
\text { Tired }\end{array}$ & $\begin{array}{c}\text { A } \alpha \text { or } \mathrm{A} \delta \text { active } \\
\text { Relaxation } \\
\text { Strengthening/- } \\
\text { Conditioning } \\
\text { Monitored } \\
\text { exercise } \\
\text { Rested }\end{array}$ \\
\hline Medical & $\begin{array}{l}\text { Extent of injury/ - } \\
\text { Pathological } \\
\text { condition }\end{array}$ & $\begin{array}{c}\text { Medication } \\
\text { Cooling/heating }\end{array}$ \\
\hline Cognitive & $\begin{array}{l}\text { Focussing on pain } \\
\text { Anxiety/fear } \\
\text { Depression } \\
\text { Negative attitude } \\
\text { Stress }\end{array}$ & $\begin{array}{c}\text { Distraction } \\
\text { Relaxation } \\
\text { Happiness } \\
\text { Positive attitude } \\
\text { Prior experience }\end{array}$ \\
\hline
\end{tabular}

Compiled from[35-37] 
Table 2. Summary of key findings from neurophysiological studies which suggest vibration is an influencing factor

\begin{tabular}{|c|c|c|c|}
\hline Author & Publication date & $\mathrm{N}$ & Relevant points \\
\hline Eckman & 1975 & 3 & Clinical case study of cyclists who developed ulnar neuropathy \\
\hline Noth & 1980 & 4 & Clinical case study of cyclists who developed deep and distal ulnar neuropathy \\
\hline Weiss & 1985 & 132 & $\begin{array}{c}\text { Groin numbness and palmarpain or paresthesias each occurred in approximately } 10 \% \\
\text { or bicycle riders during a } 500 \text { mile race }\end{array}$ \\
\hline Wilmarth & 1988 & 25 & Sensory nerve conduction velocity of the ulnar nerve following cycling \\
\hline Walker & 1988 & 1 & Clinical case study of ulnar nerve injury caused by push ups on a hard surface \\
\hline Hagberg & 1991 & 41 & $\begin{array}{c}\text { Level and intensity of vibration exposure influences recovery after carpal tunnel } \\
\text { surgery }\end{array}$ \\
\hline Richmond & 1994 & Review & $\begin{array}{l}\text { Compression neuropathy, more commonly ulnar than median, is frequent but seldom } \\
\text { produces permanent injury or deficit if promptly recognized and managed }\end{array}$ \\
\hline Goldsmith & 1994 & 47 & Primary nerves affected by vibration are small nerve fibres \\
\hline Rittweger & 2001 & 12 & 5 mins WBV results in most subjects feeling uncomfortable \\
\hline Patterson & 2003 & 25 & Cyclist's palsy occurs at high rates in both experienced and inexperienced cyclists. \\
\hline Sandén & 2010 & 155 & $\begin{array}{c}\text { no exposure-response association bet ween hand-arm vibration exposure and distal } \\
\text { neuropathy of the large myelinated fibres }\end{array}$ \\
\hline Hong & 2011 & 1 & $\begin{array}{c}\text { Clinical case study describing pain reduction in diabetic small fibre neuropathy } \\
\text { following WBV }\end{array}$ \\
\hline
\end{tabular}

There is also potential that a change in the ratio of peripheral stimulation results in 'undue perception of exertion[9]. It should also be noted that this process can be beneficial in pain reduction if large nerve fibres are not damaged or in neuropathies such as in diabetic small fibre neuropathy[35]. Therefore, while gate theory has the potential to act as an underlying mechanis $m$ for perception of a WBV experience, more studies considering the perception of WBV exercise are needed. It is of interest to note that while the potentially different frequencies of vibration during exercise, compared to that of industrial applications, in combination with reduced exposure time, might not exaggerate pre-existing conditions; the process may be uncomfortable for the participants. The key points from these studies are summarised in Table 2.

\section{Neurovascular Considerations}

While generally neurovascular injuries in the hands of athletes are rare[36], the relatively high occurrence resulting from occupational exposure to vib ration warrant s considerat ion when introducing a participant to vibration exercise.
Vibration introduced to the human body, whether whole body vibration or partial body vibration, potentially can influence peripheral vascular structure and consequently blood flow. One of the most common conditions resulting from hand/arm vibration is Raynaud's phenomenon (RP) and/or its secondary form Vibration White Finger (VWF). Both these are vasospastic conditions of the extremities for which the greatest risk occurs at frequencies 40-125 Hz[37]. Much widely available recreational vibration equip ment can operate inside this range, therefore exposure risks further vasospastic responses. Typically a vasospastic response, or excessive constriction of a blood vessel, will result in local pain, cyanosis (blue colour of the skin), pallor and altered sweat secretion[18]. As peripheral sweat glands are under the control of the sympathetic nervous system this suggests a global response as opposed to a purely local response. This hypothesis is strengthened by additional global responses to upper limb vibration, such as an increased heart rate[38], bilateral vasospastic responses to a unilateral hand vibration exposure[39] and vasospastic responses in the feet resulting from upper limb exposure to cold when assessing for hand/arm vibration syndrome[40-42]. Palmer vibration has also been shown to result in increased skin sympathetic 
activity in the region innervated by the tibial nerve and increased perspiration of the sole of the foot[43]. The responses have been attributed to both a global response via a centrally mediated sympathetic vasoconstrictor reflex and local responses within the blood vessels themselves [38]. The connection between cutaneous vibration receptors (Pacinian corpuscles) and the sympathetic nervous system has previously been identified as postganglionic sympathetic fibres within Pacinian corpuscles [44]. The connection between Pacinian corpuscles and sympathetic nervous activity was further supported by[45] who reported a constant relationship between vasospasms and the mean threshold for Pacinian corpuscle activation. It has therefore been suggested that continuous activation of Pacinian corpuscles could result in a 'reflex efferent discharge causing vasoconstriction'[39]. However, the resulting responses to vibration have been attributed to both a vasoconstrictor reflex and an active local vasodilatation, with both mechanis ms competing against each other[38]. One potential underlying mechanism influencing local vasodilatation is local release of endothelial-derived relaxing factor (EDRF) and prostacyclin[39]. The endothelium itself can be considered a dynamic interface between the vascular compartment and the extravascular space, acting in the roles of assisting in the regulation of protein flux, inflammatory cells into tissues, blood flow and prevention of thrombosis [46]. The release of EDRF can be stimulated by shear stress in isolated blood vessel sections [47], which has been confirmed by the fact that it has been shown that segments of blood vessels which are more active, i.e. experiences greater blood flow or changes in blood flow is a more potent stimulus of EDRF release non changing low flow [48]. As blood is a viscous liquid it is the principle cause of shear stress on the endothelium, particularly the blood which is contact with endothelial cell surface which does not flow at the rate of blood central to the blood vessels, however unlike mechanical strain, shear stress is focussed on the endothelium and not transferred to local tissues [46]. The mechanical stresses with in vasculature and the predicted consequences have been mathematically modelled $[49,50]$. It has also been shown that as blood flow increases an enhanced rate of prostacyclin release is observed[51]. Therefore it is conceivable that the endothelin-induced release of prostacyclin results from increased shearstress [52]. The role endothelin-1 of has been investigated due to its ability to produce sustained vasoconstriction, therefore increasing shear stress and release of EDRF, however when Endothelin-1 was introduced in the presence of a strong vasodilator (which abolished the vasoconstriction) no increase in EDRF was observed[52], which indicates that shear stress not the presence of Endothelin-1 influenced the increased release of EDRF. Based on these findings the endothelium clearly has an important role in the response to shear stresses, potentially by activating cell signalling pathways which trigger effector responses, unfortunately to date it not known if these responses are direct mechanosensors i.e. they automatically respond to stress/strain, or they are mechanosensitive i.e. they respond to local signals produced in res ponse to stress/strain[46]. The effect of shear stresses on larger vascular structures have also been investigated by assessing pulse wave velocity and blood pressure at the ankles which can be used as predictor of peripheral arterial stiffness. To completely differentiate between peripheral and central arterial stiffness is problematical, however it has been suggested that by obtaining wave velocity and blood pressure recordings at the ankles, peripheral influence would be greater[53]. The findings indicated that changes in arterial stiffness reduced circa 20 minutes after WBV exercise sustained for circa 40 mins. The authors suggested that potentially due to vasodilatation via vascular endothelial function. This hypothesis is supported by reports that vibration during cycling resulted in an increase in the release of vascular endothelial growth factor (VEGF) and Matrix metalloproteinases (endopeptidases) MMP-2 and MMP-9,[54]. Although it should be noted that VEGF release was related to the participants training status as greater releases were noted in higher trained participants. It is not known if this was due to an increased production of VEGF or a release of increased stored levels of VEGF. It is possible that these changes also occur due to increased shear stresses as vibration during exercise has been shown to increase blood flow[55-57] and increased tissue oxygenation parameters [58, 59]. However, it should be noted that although vasospastic responses to vibration have been noted in the extremities; it has not yet been established if changes in tissue oxygenation are in relation to increased blood flow or to vasospastic responses in the feet.

A final point of interest is that shear forces in blood vessels have also been shown to create mechanical risks which researchers and practitioners should be aware of. Two case studies have recently reported patients presenting with uniocular drops in $v$ ision clinically attributed to vitreous haemorrhage, the suspected cause in both cases was WBV. Bertschinger \& Dosso[60] reported the case of a 43 year old man who presented with a uniocular drop in vision, the only reported change in recent activity was the introduction WBV for a period of two weeks prior to developing the condition. More recently it has been reported[61] the case of vitreous haemorrhage with localised posterior retinal detachment in a 52 year old male. The patient presented with a uniocular drop in vision following a single session of WBV. While the authors acknowledge that causality cannot be categorically related to $\mathrm{WBV}$, previous issues such as vitreous liquefaction has been reported in workers using pneumatic drills [62] indicating there is a need for caution, particularly if interacting with people who have previously suffered from this condition, and further research into this area. The key points from these studies are summarised in Table 3. 
Table 3. Summary of key findings from neurovascular studies which suggest vibration is an influencing factor

\begin{tabular}{|c|c|c|c|}
\hline Author & $\begin{array}{l}\text { Publication } \\
\text { date }\end{array}$ & n & Relevant points \\
\hline Hyvärinen & 1973 & 43 & $\begin{array}{l}\text { Traumatic vasospastic disease is a chronic over excitation of the pacinian vibration receptors that } \\
\text { produce spastic reactions in the vasculat ure through a reflex linkage with the sympathetic nervous } \\
\text { system }\end{array}$ \\
\hline Kroemer & 1989 & Review & Frequencies of $40-125$ provide great est risk of vasospastic diseases in hands \\
\hline Aulicino & 1990 & Review & $\begin{array}{l}\text { Neurovascular injuries are rare in the athlete. Modification of protective devices, alteration of } \\
\text { technique, and education may help avoid neurovascular problems described in this article }\end{array}$ \\
\hline Sakakibara & 1990 & 5 & $\begin{array}{l}\text { Vibration exposure of the hand triggers sympathet ic activity in the tibial nerve innervating the } \\
\text { foot, and causes vasoconstriction of the toe and perspiration on the sole of the foot }\end{array}$ \\
\hline Sakakibara & 1991 & 43 & Hand-arm vibration syndrome affects circulation in the feet \\
\hline Greenstein & 1992 & 28 & Unilateral hand vibration causes bilateral vasospastic responses \\
\hline Sakakibara & 1994 & Review & $\begin{array}{l}\text { Arterial pathological changes like medial muscular hypertrophy have been observed in both the } \\
\text { fingers and the toes of hand-arm vibration patients }\end{array}$ \\
\hline Egan & 1996 & 34 & Hand vibration causes a generalised increase in sympathet ic tone in the heart and extremities. \\
\hline Mansour & 2000 & 39 & $\begin{array}{l}\text { Workers using pneumatic drills risk vibration-induced pigment deposition in the trabecular } \\
\text { meshwork and vitreous liquefaction }\end{array}$ \\
\hline Suhr & 2007 & 12 & $\begin{array}{l}\text { In conclusion, the results support the contention that mechanical stimuli differentially influence } \\
\text { factors involved in the induction of angiogenesis. }\end{array}$ \\
\hline Otsuki & 2008 & 10 & WBV acutely decreases arterial stiffness \\
\hline Bertschinger & 2008 & 1 & Clinical case study of spont aneous vitreous haemorrhage following WBV exercise \\
\hline Gillan & 2010 & 1 & Clinical case study of spont aneous vitreous haemorrhage following WBV exercise \\
\hline House & 2011 & 191 & Workers assessed for HAVS frequent ly have cold-induced vasospasm of their feet \\
\hline \multicolumn{4}{|c|}{ St udies using animals to establish underlying mechanisms for responses } \\
\hline Rubanyi & 1986 & In vitrotesting & The release of EDRF can be stimulated by shear stress in isolated blood vessel sections \\
\hline Pohl & 1986 & $\begin{array}{l}\text { Animal study } \\
\text { (dogs) }\end{array}$ & Endothelial cells act as mediators of flow-dependent dilation \\
\hline Wennmalm & 1991 & $\begin{array}{l}\text { Animal study } \\
\text { (rabbits) }\end{array}$ & $\begin{array}{l}\text { increase in blood flow facilitation of the formation of the endothelial mediators, EDRF, } \\
\text { prostacyclin and endothelin }\end{array}$ \\
\hline Lamontagne & 1992 & $\begin{array}{l}\text { Animal study } \\
\text { (rabbits) }\end{array}$ & $\begin{array}{l}\text { EDRF formation may result from the high shear stress imposed on the endothelial lining by the } \\
\text { periodic diameter reduction and from the direct deformation of the endothelium. }\end{array}$ \\
\hline
\end{tabular}

\section{Conclusions}

Despite a his tory of vibration being viewed negatively, the last two decades have seen a rise in the popularity and effective use of vibration for health and recreation. While the scope of this review includes many risk factors and areas for concern, it should be noted that the aim is not to cast dispersions or discourage the use of vibration during exercise. While there is no doubt there are potential neuromechanical, physiological and vascular issues, correct planning and implementation of exercise protocols should effectively control these risks. It should be noted that many of the published studies are older than equipment currently in use today, a consequence of technological progression which provides the primary limitation of this study. The amalgamation of research in this review was formed with the aim of creating awareness about the need for safe and effective application of vibration and how to avoid exacerbating pre-existing conditions such as carpal tunnel syndrome, ulnar neuropathies, vasospastic diseases and 
conditions of the eye such as vitreous haemorrhage. It is recommended that further research and reviews such as this are carried out for additional areas e.g. bone health; health of synovial joints; cardio-respiratory system; metabolic and endocrine systems in order for an effective pre-exercise screening and questionnaire to be developed.

\section{Conflicts of Interest and Funding}

This project was partially funded by Power Plate International Ltd and produced within the Power Plate Research Institute at the University of Greenwich at Medway.

\section{REFERENCES}

[1] M. Cardinale and M. H. Pope, "The effects of whole body vibration on humans: dangerous or advantageous?," Acta phy siologica Hungarica, vol. 90, no. 3, pp. 195-206, Jan. 2003.

[2] D. G. Dolny and G. F. C. Reyes, "Whole body vibration exercise: training and benefits.," Current sports medicine reports, vol. 7, no. 3, pp. 152-7, 2008.

[3] J. Mester, H. Kleinöder, and Z. Yue, "Vibration training: benefits and risks.," Journal of biomechanics, vol. 39, no. 6, pp. 1056-65, Jan. 2006.

[4] F. Rauch, "Vibration therapy.," Developmental medicine and child neurology, vol. 51 Suppl 4, pp. 166-8, Oct. 2009.

[5] V. B. Issurin, "Vibrations and their applications in sport. A review.," The Journal of sports medicine and phy sical fitness, vol. 45, no. 3, pp. 324-36, Sep. 2005.

[6] M. Mikhael, R. Orr, F. Amsen, D. Greene, and M. a F. Singh, "Effect of standing posture during whole body vibration training on muscle morphology and function in older adults: a randomised controlled trial.," BMC geriatrics, vol. 10, no. 1, p. 74, Jan. 2010.

[7] M. Y. Pang, "Whole body vibration therapy in fracture prevention among adults with chronic disease," World Journal of Orthopedics, vol. 1, no. 1, p. 20, 2010.

[8] M. Cardinale and J. Wakeling, "Whole body vibration exercise: are vibrations good for you?," British journal of sports medicine, vol. 39, no. 9, pp. 585-9; discussion 589, Sep. 2005.

[9] J. Rittweger, "Vibration as an exercise modality: how it may work, and what its potential might be.," European journal of applied phy siology, vol. 108, no. 5, pp. 877-904, Mar. 2010.

[10] D. J. J. Cochrane, "Vibration exercise: the potential benefits.," Journal of Sports Science and Medicine, vol. 32, no. May 2010, pp. 19-30, Feb. 2011.

[11] C. Lorenzen, W. Maschette, M. Koh, and C. Wilson, "Inconsistent use of terminology in whole body vibration exercise research.," Journal of science and medicine in sport, vol. 12 , no. 6 , pp. 676-8, Nov. 2009.
[12] C. Hulshof and B. V. van Zanten, "Whole-body vibration and low-back pain. A review of epidemiologic studies.," International archives of occupational and environmental health, vol. 59, no. 3, pp. 205-20, Jan. 1987.

[13] T. E. Hill, G. T. Desmoulin, and C. J. Hunter, "Is vibration truly an injurious stimulus in the human spine?," Journal of biomechanics, vol. 42, no. 16, pp. 2631-5, Dec. 2009.

[14] Y. Allieu and E. Mackinnon, S, Nerve Compression Syndromes of the Upper Limb. Martin Dunitz, 2002.

[15] P. B. Eckman, G. Perlstein, and P. H. Altrocchi, "Ulnar Neuropathy in Bicycle Riders," Archives of Neurology, vol. 32, no. 2, pp. 130-131, Feb. 1975

[16] J. Noth, V. Dietz, and K.-H. Mauritz, "Cyclist's palsy," Journal of the Neurological Sciences, vol. 47, no. 1, pp. 111-116, Jul. 1980.

[17] B. D. Weiss, "Nontraumatic injuries in amateur long distance bicy clists," The American Journal of Sports Medicine, vol. 13, no. 3, pp. 187-192, Jun. 1985.

[18] D. Dawson, M. Hallett, and J. Wilbourn, A, Entrapment Neuropathies. Lippincott-Raven, 1999.

[19] M. A. Wilmarth and S. G. Nelson, "Distal sensory latencies of the ulnar nerve in long distance bicy clists: pilot study*.," The Journal of orthopaedic and sports phy sical therapy, vol. 9, no. 11, pp. 370-4, Jan. 1988.

[20] D. R. Richmond, "Handlebar problems in bicycling.," Clinics in sports medicine, vol. 13, no. 1, pp. 165-73, Jan. 1994.

[21] M. Pecina, J. Krmpotic-Nemanic, and A. Markiewitz, Tunnel Syndromes, Peripheral Nerve Compression Sundromes, Second. CRC Press, 1997.

[22] J. M. M. Patterson, M. M. Jaggars, and M. I. Boyer, "Ulnar and Median Nerve Palsy in Long-distance Cyclists: A Prospective Study," Am. J. Sports Med., vol. 31, no. 4, pp. 585-589, Jul. 2003.

[23] F. O. Walker and B. T. Troost, "Push-up Palmar Palsy," JAMA: The Journal of the American Medical Association, vol. 259, no. 1, pp. 45-46, Jan. 1988.

[24] R. A. Werner, C. Bir, and T. J. Armstrong, "Reverse Phalen's maneuver as an aid in diagnosing carpal tunnel syndrome.," Archives of phy sical medicine and rehabilitation, vol. 75, no. 7, pp. 783-6, Jul. 1994.

[25] J. A. Durkan, "A new diagnostic test for carpal tunnel syndrome." The Journal of bone and joint surgery. American volume, vol. 73, no. 4, pp. 535-8, Apr. 1991.

[26] J. González del Pino, A. D. Delgado-Martínez, I. González González, and A. Lovic, "Value of the carpal compression test in the diagnosis of carpal tunnel syndrome.," Journal of hand surgery (Edinburgh, Scotland), vol. 22, no. 1, pp. 38-41, Feb. 1997.

[27] T. Strömberg, L. B. Dahlin, a Brun, and G. Lundborg, "Structural nerve changes at wrist level in workers exposed to vibration.," Occupational and environmental medicine, vol. 54, no. 5, pp. 307-11, May 1997.

[28] R. J. Macgregor, S. K. Sharpless, and M. W. Luttges, "A pressure vessel model for nerve compression." Journal of the neurological sciences, vol. 24, no. 3, pp. 299-304, Mar. 1975. 
[29] M. Hagberg, A. Nyström, and B. Zetterlund, "Recovery from symptoms after carpal tunnel syndrome surgery in males in relation to vibration exposure.," The Journal of hand surgery, vol. 16, no. 1, pp. 66-71, Jan. 1991.

[30] R. Melzack and P. D. Wall, "Pain mechanisms: a new theory.," Science (New York, N.Y.), vol. 150, no. 3699, pp.971-9, Nov. 1965.

[31] P. D. Wall, "The gate control theory of pain mechanisms. A re-examination and re-statement.," Brain $\square$ : a journal of neurology, vol. 101, no. 1, pp. 1-18, Mar. 1978.

[32] J. Rittweger, H. Schiessl, and D. Felsenberg, "Oxygen uptake during whole-body vibration exercise: comparison with squatting as a slow voluntary movement," European Journal of Applied Physiology, vol. 86, no. 2, pp. 169-173, Dec. 2001.

[33] P. C. Goldsmith et al., "Cutaneous nerve fibre depletion in vibration white finger.," Journal of the Royal Society of Medicine, vol. 87, no. 7, pp. 377-81, Jul. 1994.

[34] H. Sandén et al., "Nerve conduction in relation to vibration exposure - a non-positive cohort study.," Journal of occupational medicine and toxicology (London, England), vol. 5, p. 21, Jan. 2010.

[35] J. Hong, M. J. Barnes, and N. J. Kessler, "Case study: Use of vibration therapy in the treatment of diabetic peripheral small fiber neuropathy," International Journal of Diabetes Mellitus, vol. Article in, no. Press, Feb. 2011.

[36] P. L. Aulicino, "Neurovascular injuries in the hands of athletes.," Hand clinics, vol. 6, no. 3, pp. 455-66, Aug. 1990.

[37] K. Kroemer, "Cumulative trauma disorders: their recognition and ergonomics measures to avoid them," Applied ergonomics, vol. 20, no. 4, pp. 274-280, 1989.

[38] C. E. Egan, B. H. Espie, S. McGrann, K. M. McKenna, and J. a Allen, "Acute effects of vibration on peripheral blood flow in healthy subjects.," Occupational and environmental medicine, vol. 53, no. 10, pp. 663-9, Oct. 1996.

[39] D. Greenstein and R. C. Kester, "Acute vibration--its effect on digital blood flow by central and local mechanisms.," Proceedings of the Institution of Mechanical En gineers. Part $\mathrm{H}$, Journal of engineering in medicine, vol. 206, no. 2, pp. 105-8, Jan. 1992.

[40] H. Sakakibara, T. Hashigu chi, M. Furuta, T. Kondo, M. Miyao, and S. Yamada, "Circulatory disturbances of the foot in vibration syndrome.," International archives of occupational and environmental health, vol. 63 , no. 2, pp. 145-8, Jan. 1991.

[41] H. Sakakibara, "Sympathetic responses to hand-arm vibration and symptoms of the foot.," Nagoya journal of medical science, vol. 57 Suppl, pp. 99-111, May 1994.

[42] R. House et al., "Vasospasm in the feet in workers assessed for HAVS.," Occupational medicine (Oxford, England), vol. 61, no. 2, pp. 115-20, Mar. 2011.

[43] H. Sakakibara et al., "Skin sympathetic activity in the tibial nerve triggered by vibration applied to the hand.," International archives of occupational and environmental health, vol. 62, no. 6, pp. 455-8, Jan. 1990.

[44] M. Santini, Y. Ibata, and G. D. Pappas, "The fine structure of the sympathetic axons within the Pacinian corpuscle.," Brain research, vol. 33, no. 2, pp. 279-87, Oct. 1971.
[45] J. Hyvärinen, I. Pyykkö, and S. Sundberg, "Vibration frequencies and amplitudes in the aetiology of traumatic vasospastic disease.," Lancet, vol. 1, no. 7807, pp. 791-4, Apr. 1973.

[46] M. H. Ali and P. T. Schumacker, "Endothelial responses to mechanical stress: where is the mechanosensor?" Critical care medicine, vol. 30, no. 5 Suppl, pp. S198-206, May 2002.

[47] G. M. Rubanyi, J. C. Romero, and P. M. Vanhoutte, "Flow-induced release of endothelium-derived relaxing factor.," The American journal of phy siology, vol. 250, no. 6 Pt 2, pp. H1145-9, Jun. 1986.

[48] U. Pohl, J. Holtz, R. Busse, and E. Bassenge, "Crucial role of endothelium in the vasodilator response to increased flow in vivo.," Hypertension, vol. 8, no. 1, pp. 37-44, Jan. 1986.

[49] Z. Yue, H. Kleinöder, M. de Marées, U. Speicher, P. Wahl, and J. Mester, "On the Cardiovascular Effects of Whole-Body Vibration Part II. Lateral Effects: Statistical Analysis," Studies in Applied Mathematics, vol. 119, no. 2, pp.111-125, Aug. 2007.

[50] Z. Yue and J. Mester, "On the Cardiovascular Effects of Whole-Body Vibration Part I. Longitudinal Effects: Hydrodynamic Analysis," Studies in Applied Mathematics, vol. 119, no. 2, pp. 95-109, Aug. 2007.

[51] A. Wennmalm, G. Benthin, E. Karwatowska-Prokopczuk, J. Lundberg, and A. S. Petersson, "Release of endothelial mediators and sympathetic transmitters at different coronary flow rates in rabbit hearts.," The Journal of Phy siology, vol. 435, no. 1, p. 163, Apr. 1991.

[52] D. Lamontagne, U. Pohl, and R. Busse, "Mechanical deformation of vessel wall and shear stress determine the basal release of endothelium-derived relaxing factor in the intact rabbit coronary vascular bed.," Circulation research, vol. 70, no. 1, pp. 123-30, Jan. 1992.

[53] T. Otsuki, Y. Takanami, W. Aoi, Y. Kawai, H. Ichikawa, and T. Yoshikawa, "Arterial stiffness acutely decreases after whole-body vibration in humans.," Acta physiologica (Oxford, England), vol. 194, no. 3, pp. 189-94, Nov. 2008.

[54] F. Suhr et al., "Effects of short-term vibration and hypoxia during high-intensity cy cling exercise on circulating levels of angiogenic regulators in humans.," Journal of applied physiology (Bethesda, Md. $\square:$ 1985) vol. 103, no. 2, pp. 474-83, Aug. 2007.

[55] K. Kerschan-Schindl et al., "Whole-body vibration exercise leads to alterations in muscle blood volume.," Clinical physiology (Oxford, England), vol. 21, no. 3, pp. 377-82, May 2001.

[56] D. Lohman III, E.B..Petrofsky, J.S. Maloney-Hinds, C. Betts-Schwab, H. Thorpe, "The effect of whole body vibration on lower extremity skin blood flow in normal subjects," Med Sci Monit, vol. 13, no. 2,p. 76, 2007.

[57] N. Lythgo, P. Eser, P. de Groot, and M. Galea, "Whole-body vibration dosage alters leg blood flow.," Clinical phy siology and functional imaging, vol. 29, no. 1, pp. 53-9, Jan. 2009.

[58] M. Cardinale, M. Ferrari, and V. Quaresima, "Gastrocnemius medialis and vastus lateralis oxy genation during whole-body vibration exercise.," Medicine and science in sports and exercise, vol. 39, no. 4, pp. 694-700, Apr. 2007.

[59] A. Coza, B. M. Nigg, and J. F. Dunn, "Effects of vibrations on 
gastrocnemius medialis tissue oxygenation.," Medicine and science in sports and exercise, vol. 43, no. 3, pp. 509-15, Mar. 2011.

[60] D. R. Bertschinger and A. Dosso, "Vitreous hemorrhage and whole-body vibration training--is there an association?," Journal français d'ophtalmologie, vol. 31, no. 8, p. e17, Oct. 2008.
[61] S. Gillan, S. Sutherland, and C. Cormack G., "Vitreous Hemorrhage After Whole-Body Vibration Training," RETINAL Cases \& Brief Reports: , vol. 5, no. 2, pp. 130-131, 2011.

[62] A. M. Mansour, S. H. Uwaydat, and A. S. Khouri, "Ocular sequelae of pneumatic drills.” Eye (London, En gland), vol. 14 ( Pt 1), pp. 64-6, Feb. 2000. 